\title{
Internet Addiction Among Arts And Science College Students
}

\author{
Dr. P.SURESH PRABU, \\ ,K.S.R College of Education,Tiruchengode-637215,Namakkal (Dt),Tamilnadu, India.
}

\begin{abstract}
Internet addiction disorder (IAD) is now more commonly called problematic internet use (PIU) or compulsive internet use (CIU). Other overlapping terms include internet overuse, problematic computer use or pathological computer use Disorder. These terms avoid the word addiction and are not limited to any single cause, but only reflect a general statement about excessive computer use that interferes with daily life. Other habits such as reading, playing computer games, or watching very large numbers of internet videos or movies are all troubling only to the extent that these activities interfere with normal life. The purpose of the study is to find out the level of internet addiction among Arts and Science college students. The present study consists of 250 college students studying in Arts and Science colleges situated in Namakkal District of Tamil Nadu. The sample was selected by using simple random sampling technique. The main findings of the study reveals that the Arts and Science college students are having average level of internet addiction and irrespective of sub samples of the Arts and Science college students are having average level of internet addiction. The internet addiction level of male students is higher than their counter part. The internet addiction level of urban students is higher than their counter part. The internet addiction level of private college students is higher than their counter part. The internet addiction level of science subject students is higher than their counter part.
\end{abstract}

KEY WORD- Internet Addiction

\section{INTERNET ADDICTION}

Internet addiction is described as an impulse control disorder, which does not involve use of an intoxicating drug and is very similar to pathological gambling. Some Internet users may develop an emotional attachment to on-line friends and activities they create on their computer screens. Internet users may enjoy aspects of the Internet that allow them to meet, socialize, and exchange ideas through the use of chat rooms, social networking websites, or "virtual communities." Other Internet users spend endless hours researching topics of interest Online or "blogging". Blogging is a contraction of the term "Web log", in which an individual will post commentaries and keep regular chronicle of events. It can be viewed as journaling and the entries are primarily textual.

Similar to other addictions, those suffering from Internet addiction use the virtual fantasy world to connect with real people through the Internet, as a substitution for real-life human connection, which they are unable to achieve normally.

Internet addiction is a growing epidemic characterized by a compulsive desire to interact online through internet gaming, gambling, cybersex, social networking or compulsive surfing of the web. According to Dr. Kimberly Young, the first psychologist to document internet addiction, these disorders are similar to impulse-control disorders. Meeting five of the following symptoms can lead to a diagnosis of internet addiction disorder:

- Feeling preoccupied with the internet. (thinking about your previous online activity or anticipating the next time you will go online)

- Feeling a desire to use the internet for increased amounts of time in order to achieve satisfaction with your use of the web. (similar to tolerance that is addressed in substance abuse problems)

- Having a lack of control in efforts to stop using the internet or to cut back use.

- Feeling restless, irritable, depressed or otherwise moody when not using the internet.

- Staying online longer than you originally planned to.

- Jeopardized a job, relationship, educational opportunity or other important opportunity because of the internet.

- Lying to friends, family members or others in an effort to conceal the true amount of time that you spend online or your actual activities while online.

- Using the internet as a way of escaping reality, escaping problems or relieving a negative mood. 


\section{Types of Internet Addiction Disorders}

An addiction to the internet can come in various forms. Most of the time, internet addiction is characterized by the activity that an individual is taking part in while they are online such as shopping, socializing or gaming. Internet addiction disorder includes:

- Net Compulsions - this includes compulsive gambling, gaming, shopping, trading stocks or other obsessive use of the internet that interferes with your work or home, relationships or financial well-being.

- Cybersex Addiction - compulsive use of the internet to take part in adult chat rooms, fantasy role playing sites, or to watch internet pornography.

- Cyber-Relationship Addiction - taking part in social networks, chat rooms and virtual messaging online to a point in which these online relationships mean more than real-life relationships with friends or family members.

- General Computer Addiction - obsessively playing on the computer, not necessarily online. This may include playing games such as Solitaire or programming a computer obsessively.

- Compulsive Web Surfing - obsessively surfing the web or a database to a point in which you take time from your friends, family members or regular daytime tasks at work or home.

\section{SYMPTOMS OF INTERNET ADDICTION}

The symptoms of internet addiction may not be visibly present or a person may only show a few of the signs of internet addiction. There is not a set amount of time spent online each day that can be used to describe the presence of an addiction to the internet. This amount of time will be different for each individual.

- Spending more time online than you even realize. Do you often find that you wind up online longer than had anticipated? If you find that your planned time online goes from being a few minutes to actually spending hours online, you might have a problem.

- Isolating yourself from friends or family members to spend time online. Do you spend more time socializing online than you do in real life? You might have an addiction to the internet if you are isolating yourself from friends or family members in order to spend time online.

- Becoming defensive about your time spent online. If you feel like you have to be defensive about the time that you spend online or you feel like you have to lie to your friends or family members about what you are doing online than you might have a problem.

- Difficulty completing tasks at work or at home because you spend too much time surfing the web. If you have trouble focusing on your priorities or you find that your time online has made you slack on your tasks at work or at home you you may be suffering from an internet addiction.

- Euphoric feelings when involved with internet activities. Do you use the internet to reduce stress, gain sexual gratification or excitement? If you use the internet to boost your mood or to feel better you may have a problem.

\section{CAUSES OF INTERNET ADDICTION}

People become addicted to the internet for a number of different reasons. Most of the time, the urge to compulsive use the internet is the result of a desire to manage unpleasant feeling such as depression, anxiety, stress or loneliness. Some feel socially inept in the real world and turn to social media interaction as a means of feeling close to people, while others may lose themselves online in an effort to temporarily feel better. Unfortunately, the internet, when used compulsively, can lead to many consequences.

- Self-medication for a mental health disorder. Many people use the internet to mask anxiety, depression, or other mental illness.

- Information addicts. Some people have an intense hunger for knowledge and the internet provides immediate access to tons of information that can be very attractive for information addicts.

- Anxiety or social disorders. Some people have anxiety when they are face to face with people or suffer from other social disorders that make it difficult for them to interact in real life but easier to interact online.

- Loneliness. Many people, especially those who do not have a companion, interact online to fulfill a void that causes them to feel lonely.

- Shifting from a real world addiction. Many people who suffer from a real world addiction to shopping or gambling will shift their addictions to an online version such as internet gambling or excessive shopping online.

\section{EFFECTS OF INTERNET ADDICTION}

In many ways, internet addiction can be compared to an addiction to drugs or alcohol in that, internet addiction causes a desire to use the internet more and more in order to produce a satisfactory effect. This is similar to the way an alcoholic may need to drink more alcohol in order to feel the benefits of the substance or 
the way that a drug addict may use more drugs in an effort to produce the same "high." Internet addicts become dependent on the use of cyberspace in order to feel normal.

Internet addicts struggle to control their behaviors and often experience great despair over their consistent failure to escape their addictive behaviors. A loss of self-esteem and a burning desire to escape can lead the addict further into their addiction sending them into a whirlwind of social anguish, relationship failure and emotional pain. In the end, the internet addiction will cause a sense of powerlessness for the addict.

\section{PREVENTING INTERNET ADDICTION IN CHILDREN AND TEENS}

In today's society where the use of the internet is present in schools, at home and on the go, children and teens are subjected to a whole new potential for internet addiction that was not necessarily present for adults until recently. Preventing internet addiction in children and teens can be more difficult that you may think. As a parent, there is a fine line between the level of internet usage that is acceptable and what is not for a child or teen.

- Limit internet usage to include minimal use for social interaction.

- Internet use should focus on the need to use the internet for school assignments and research.

- Limit internet gaming

- Monitor internet use and set boundaries

- Keep internet usage restricted to specific areas of the home

- Talk to your child about anxiety, depression, school, and other potential triggers that may be causing additional internet use

- Seek help form a doctor, friend or professional if your child seems to be spending too much time online

\section{REVIEW OF RELATED STUDIES}

Chien Chou et.al., (2005). A Review of the Research on Internet Addiction. Research indicates that maladaptive patterns of Internet use constitute behavioral addiction. This article explores the research on the social effects of Internet addiction. There are four major sections. The Introduction section overviews the field and introduces definitions, terminology, and assessments. The second section reviews research findings and focuses on several key factors related to Internet addiction, including Internet use and time, identifiable problems, gender differences, psychosocial variables, and computer attitudes. The third section considers the addictive potential of the Internet in terms of the Internet, its users, and the interaction of the two. The fourth section addresses current and projected treatments of Internet addiction, suggests future research agendas, and provides implications for educational psychologists.

Brenner, V. (1997). Psychology of computer use: XLVII. Parameters of Internet use, abuse and addiction: The first 90 days of the Internet usage survey. While the addictive potential of Internet usage is a topic that has attracted a great deal of attention, as yet little research has addressed this topic. Preliminary data from the Internet Usage Survey shows that most of the 563 users reported instances of Internet use interfering with other aspects of their lives, most commonly problems with managing time. A subgroup of users endorsed multiple usage-related problems, including several similar to those found in addictions. Younger users tended to have experienced more problems.

J Rob J de Leeuw et.al., (2010). Internet and Game Behaviour at a Secondary School and a Newly Developed Health Promotion Programme: A Prospective Study. This study investigated the Internet and game use of secondary school children, the compulsiveness of their use and the relationship with other health behaviours. It also evaluated the preliminary results of a recently developed school health promotion programme, implemented at a secondary school in the Netherlands in January 2008. This programme is one of the first to combine seven health behaviours in one educational programme and is a pilot project for a casecontrol study. A total of 475 secondary school children completed an extensive questionnaire before and a year after starting the programme. Of these children, 367 were in first, second and third grade; the grades in which the lessons about internet and game behaviour were implemented. Questionnaires contained questions about personal information, Internet and game use (Compulsive Internet Use Scale), and other health behaviours (alcohol use, physical activity, psychosocial wellbeing and body mass index). Heavy Internet use was significantly associated with psychosocial problems, and heavy game use was significantly associated with psychosocial problems and less physical activity. No relationship was found with alcohol use or body mass index. The time spent on Internet (hours/day) and the number of pathological Internet users increased during the study. The number of game users decreased but heavy game use increased. 
Fatih Canan et.al., (2012). The Association between Internet Addiction and Dissociation among Turkish College Students. This study aimed to investigate Internet use patterns and Internet addiction among young adult university students and to examine the correlation between excessive Internet use and dissociative symptoms. The study was conducted among 1034 students, aged between 18 and 27 years. Internet Addiction Scale, Dissociative Experiences Scale, and a sociodemographic query form were used in the collection of data. Pearson correlation analysis, the $t$ test, and $\chi^{2}$ test were used for data analysis. According to the Internet Addiction Scale, 9.7\% of the study sample was addicted to the Internet. The Pearson correlation analysis results revealed a significant positive correlation between dissociative experiences and Internet addiction $(\mathrm{r}=0.220 ; \mathrm{P}<.001)$ and weekly Internet use $(\mathrm{r}=0.227 ; \mathrm{P}<.001)$. Levels of Internet addiction were significantly higher among male students than female students $(\mathrm{P}<.001)$. The Internet use pattern also differed significantly between sexes. According to the results of this study, Internet addiction is a relatively frequent phenomenon among young adult college students in Turkey. Excessive Internet use is associated with higher levels of dissociative symptoms.

\section{NEED AND SIGNIFICANCE OF THE STUDY}

The internet can provide access to some valuable tools, interesting stories, exciting games and informative content but, when used in excess, the internet has the ability to interfere with work, life, relationships, and daily routines. Internet addiction disorder is a potentially dangerous condition that affects individuals who spend large amounts of time online socializing with friends, playing games, gambling or just surfing the web despite the negative consequences that result from spending so much time online. Some suffering from Internet addiction may create on-line personas or profiles where they are able to alter their identities and pretend to be someone other than himself or herself. Those at highest risk for creation of a secret life are those who suffer from low-self esteem feelings of inadequacy, and fear of disapproval. Such negative self-concepts lead to clinical problems of depression and anxiety.

Nowadays internet addiction among college students are problematic situation in their life. Therefore, the present study has high need and importance.

\footnotetext{
A. STATEMENT OF THE PROBLEM

The problem undertaken by the investigator is stated as

"INTERNET ADDICTION AMONG ARTS AND SCIENCE COLLEGE STUDENTS". OBJECTIVES OF THE STUDY

The investigator of the present study framed the following objectives:

1. To find out the level of internet addiction among Arts and Science college students in Namakkal district of Tamilnadu.

2. To find out whether there is significant difference between the following sub samples with respect to internet addiction.

a) Gender [Male / Female]

b)Locality [Rural / Urban]

Management [ Government / Private] and

Subject [Science / Arts]
}

\section{HYPOTHESES OF THE STUDY}

The investigator of the present study framed the following hypotheses:

1. There is significant mean difference between male and female students with respect to internet addiction.

2. There is significant mean difference between rural and urban area students with respect to internet addiction.

3. There is significant mean difference between Government and private college students with respect to internet addiction.

4. There is significant mean difference between science and arts subject students with respect to internet addiction.

\section{THE METHOD}

In the present study, the investigator applied normative survey as a method. The normative survey method studies, describes and interprets what exists at present. 


\section{SAMPLE}

A sample is a small proportion of a population selected for observation and analysis. By observing the characteristics of the sample, one can make certain inferences about the characteristics of the population from which it is drawn.

The present study consists of 250 college students studying in Arts and Science colleges situated in Namakkal District of Tamil Nadu. The sample was selected by using simple random sampling technique. The sample forms a representative sample of the entire population.

\section{TOOL USED}

The investigator of the present study selected and used the internet addiction scale was constructed and standardized by 'Dr.Kimberley' for data collection.

\section{STATISTICAL TECHNIQUES USED}

For the analysis of the data, the following statistical techniques have been used.

a. $\quad$ Descriptive analysis (Mean \& S.D) and

b. Differential analysis (' $\mathrm{t}$ ' test)

\section{TESTING OF HYPOTHESESTABLE - 1SHOWING THE MEAN AND STANDARD DEVIATION OF INTERNET ADDICTION SCORES OF ARTS AND SCIENCE COLLEGE STUDENTS}

\begin{tabular}{|c|c|c|c|c|c|c|}
\hline Variable & Sample & $\mathbf{N}$ & Mean & S.D & $\begin{array}{l}t- \\
\text { value }\end{array}$ & $\begin{array}{l}\text { Significant } \\
\text { 0.05 level }\end{array}$ \\
\hline \multirow{2}{*}{ Gender } & Male & 65 & 33.09 & 8.31 & \multirow{2}{*}{4.69} & \multirow{2}{*}{ Significant } \\
\hline & Female & 185 & 27.00 & 10.74 & & \\
\hline \multirow{2}{*}{ Locality } & Rural & 188 & 28.48 & 11.07 & \multirow{2}{*}{0.28} & \multirow{2}{*}{ Not Significant } \\
\hline & Urban & 62 & 28.87 & 8.58 & & \\
\hline \multirow[b]{2}{*}{ Management } & Government & 150 & 26.32 & 11.05 & \multirow[b]{2}{*}{4.90} & \multirow[b]{2}{*}{ Significant } \\
\hline & Private & 100 & 31.08 & 9.41 & & \\
\hline \multirow{2}{*}{ Subject } & Science & 139 & 28.72 & 9.73 & \multirow{2}{*}{1.12} & \multirow{2}{*}{ Not Significant } \\
\hline & Arts & 111 & 27.13 & 12.16 & & \\
\hline
\end{tabular}

XII.

SUMMARY OF FINDINGS

The following are the main findings of the present investigation.

1. The Arts and Science college students are having average level of internet addiction and irrespective of sub samples of the Arts and Science college students are having average level of internet addiction.

2. Male and female students differ significantly in their internet addiction scores.

3. Rural and urban area students do not differ significantly in their internet addiction scores.

4. Government and private college students differ significantly in their internet addiction scores.

5. Science and Arts students do not differ significantly in their internet addiction scores. 


\section{CONCLUSION}

The present study reveals that the Arts and Science college students are having average level of internet addiction and irrespective of sub samples of the Arts and Science college students are having average level of internet addiction. The internet addiction level of male students is higher than their counter part. The internet addiction level of urban students is higher than their counter part. The internet addiction level of private college students is higher than their counter part. The internet addiction level of science subject students is higher than their counter part.

\section{EDUCATIONAL IMPLICATIONS}

The result of the study shows that the level of Arts and Science students internet addiction, Internet addiction results in personal, family, academic, financial, and occupational problems that are characteristic of other addictions. Impairments of real life relationships are disrupted as a result of excessive use of the Internet. Individuals suffering from Internet addiction spend more time in solitary seclusion, spend less time with real people in their lives, and are often viewed as socially awkward. Arguments may result due to the volume of time spent on-line. Those suffering from Internet addiction may attempt to conceal the amount of time spent on-line, which results in distrust and the disturbance of quality in once stable relationships. So the college students are aware about internet addiction.

\section{REFERENCES}

[1] Brenner, V. Psychology of computer use: XLVII. Parameters of Internet use, abuse and addiction: The first 90 days of the Internet usage survey. Psychol. Rep. 1997; 80: 879-882.

[2] Chien Chou, Linda Condron, John C. Belland. A Review of the Research on Internet Addiction. Educational Psychological Review, December 2005 ; 17: 363-388.

[3] Fatih Canan, Ahmet Ataoglu, Adnan Ozcetin, Celalettin Icmeli. The Association between Internet Addiction And Dissociation Among Turkish College Students. Comprehensive Psychiatry, July 2012; 53: $422-426$

[4] J Rob J deLeeuw, Marieke deBruijn, Gerdien H deWeert-vanOene, August JP Schrijvers. Internet And Game Behaviour At A Secondary School and a Newly Developed Health Promotion Programme: A Prospective Study. BMC,December 2010; 10:544. 